Western University

Scholarship@Western

Human Environments Analysis Lab (HEAL)

$2-2013$

A comparison of injuries, crashes, and outcomes for pediatric rear occupants in traffic motor vehicle collisions

Tanya C. Stewart

Kevin McClafferty

Michael Shkrum

Jean-Louis Comeau

Jason A. Gilliland

See next page for additional authors

Follow this and additional works at: https://ir.lib.uwo.ca/healpub 


\section{Authors}

Tanya C. Stewart, Kevin McClafferty, Michael Shkrum, Jean-Louis Comeau, Jason A. Gilliland, and Douglas Fraser 


\title{
A comparison of injuries, crashes, and outcomes for pediatric rear occupants in traffic motor vehicle collisions
}

\author{
Tanya Charyk Stewart, MSc, Kevin McClafferty, BESc, Michael Shkrum, MD, Jean-Louis Comeau, BEng, \\ Jason Gilliland, PhD, and Douglas D. Fraser, MD, PhD, London, Ontario, Canada
}

\begin{abstract}
BACKGROUND:
This study was initiated was initiated to describe pediatric rear-occupant motor vehicle collision (MVC) injuries, including injury patterns and outcomes as well as characteristics associated with severe injury to the head and abdomen.

METHODS: A retrospective cohort of severely injured (Injury Severity Score [ISS] $>12$ ) pediatric (age $<18$ years) patients involved in a traffic MVC as a rear occupant and treated at one of two Ontario trauma centers (2001-2010) was studied was studied. Demographic, injury, crash and outcome data were obtained from the trauma registries. Data were statistically compared by two pediatric age groups: children ( $0-8$ years; requiring a child or booster seat) versus adolescents (9-17 years; requiring a lap-shoulder belt).

RESULTS: $\quad$ There were 36 children (34\%) and 70 adolescents (66\%) severely injured as rear occupants in MVCs. Despite similar ISS $(p=0.716)$ and mortality rates $(p=0.680)$ between age groups, there were significant differences in injury patterns and risk factors. Children were more likely to have severe head injuries ( $78 \%$ vs. $39 \%, p<0.001)$ associated with a lack of an age-appropriate child restraints (odds ratio [OR], 3.5; 95\% confidence interval [CI], 1.1-10.8; $p=0.029$ ), middle seating $(\mathrm{OR}, 6.2 ; 95 \% \mathrm{CI}, 1.5-26.1 ; p=0.013)$, and side-impact crashes $(p=0.007)$. Adolescents were more likely to have severe abdominal injuries $(23 \%$ vs. $6 \%, p<0.001)$ associated with the use of lap-shoulder belts (OR, 3.8; $95 \%$ CI, 1.1-13.3; $p=0.034)$, single-vehicle MVCs $(p=0.007)$, and vehicle extrications $(p=0.035)$.

CONCLUSION: $\quad$ While safer than the front seat for children, additional study is needed on the restraint systems and the potential for injury to pediatric rear occupants in an MVC. Our data suggest that pediatric age groups differ in injuries, risk factors, and MVC impacts. Recommendations for improved protection of child occupants and preferred seating positions are required. (J Trauma Acute Care Surg. 2013;74: 628-633. Copyright $\odot 2013$ by Lippincott Williams \& Wilkins)
\end{abstract}

LEVEL OF EVIDENCE: Epidemiologic study, level III.

KEY WORDS: $\quad$ Children and adolescents; motor vehicle collision; injuries; injury prevention and control; rear occupants.

$\mathrm{M}$ otor vehicle collisions (MVCs) are the leading cause of severe pediatric trauma and deaths. MVCs account for $18 \%$ of all pediatric injury admissions, ${ }^{1} 48 \%$ of severe trauma to children and adolescents treated at trauma centers, ${ }^{2}$ and $55 \%$ of in-hospital pediatric deaths. ${ }^{1}$ Research and injury prevention programs to decrease MVCs and related injuries are a priority for trauma centers, ${ }^{3}$ the automotive industry, and government regulatory bodies, to ensure vehicles are safe for the youngest, most vulnerable occupants.

Crashworthiness and child occupant protection are evaluated in laboratory testing with crash test dummies in various seating arrangements, restraint systems, and collision types. Test validation with real-world injury data is of particular importance in children because anthropometric dummies for children do not accurately reflect unique anatomic, physiologic, and behavioral variations during development. ${ }^{4}$ Examples of these developmental variations include changes in height,

Submitted: July 27, 2012, Revised: August 29, 2012, Accepted: August 30, 2012. From the Trauma Program (T.C.S.), London Health Sciences Centre; Departments of Surgery (T.C.S.), Pathology (K.M.,M.S.), Geography (J.G.), and Pediatrics (J.G., D.D.F.), School of Health Studies (J.G.), Western University; Children's Health Research Institute (J.G., D.D.F.); Centre for Critical Illness Research (D.D.F.), London, Ontario; and Transport Canada (J.-L.C.), Gatineau, Quebec, Canada.

Address for reprints: Tanya Charyk Stewart, MSc, Trauma Program, London Health Sciences Centre, 800 Commissioners Rd East, London, ON, Canada, N6A 5W9; email: tanya.charyk@lhsc.on.ca.

DOI: $10.1097 /$ TA.0b013e31827d606c weight, body mass index, center of gravity, body proportions, and muscle development with younger children having a larger head and weaker neck and shoulder support. ${ }^{5}$

It is commonly suggested that the rear seat is the safest place for a child occupant, and in fact, all manufacturers of air bag equipped vehicles provide information on the dangers of frontal air bags for children and explicitly state that the back seat is the safest place for children. While it has been well established that the rear seat is safer for children than in the front ${ }^{6-9}$ safety testing on the design of the rear seat and performance of accompanying restraint systems is limited. Front occupants have benefited from regulations, including dynamic crash testing, which optimize vehicle restraint systems for the front seating positions, yet there are no dynamic crash test requirements for rear-seat occupants. As a result, there has been no integration of seat and restraint design in the rear, as has been accomplished for the front seat. ${ }^{10,11}$

The risk of severe intra-abdominal and spinal cord injury or "seatbelt syndrome" in children and teens in rear seat has been well established. ${ }^{12,13}$ While the rear seat is preferred to the front because it is protective for many injury types for children 12 years and younger, ${ }^{6-9}$ there is still substantial risk of injury for children in the rear of the vehicle, particularly for those who have outgrown the ability to use booster seats. ${ }^{14}$ Having children appropriately restrained, in the rear seat, is always preferred to unrestrained, which puts children at unnecessarily high risk of injury, greater than

I Trauma Acute Care Surg Volume 74, Number 2 
three times the risk of injury compared with restrained occupants. ${ }^{15,16}$ However, because the use of restraints in youth is at times suboptimal and not age appropriate, there is still a need to better understand the potential for injury and protection offered by restraint systems for pediatric rear occupants. Age-appropriate restraints have been shown to be more important for safety than the rear seating position, but they work synergistically to protect child occupants. ${ }^{15}$ The interaction of rear-facing child restraints with the interior of motor vehicles has also been the focus of recent investigation. ${ }^{17}$

Given the limited data on restraint system efficacy for children and adolescent rear occupants as well as actual protection offered to mitigate crash injury within the rear seat of passenger vehicles, there is critical need for both laboratory and real-world data in the pediatric population to help guide the development of pediatric safety systems for the rear seat. ${ }^{18}$ Therefore, the objective of this study was to describe the injury patterns, crash characteristics, and outcomes in severely injured pediatric rear occupants treated at one of two trauma centers. The patient population was separated into two age groups, children requiring child/booster seats and adolescents requiring lap-shoulder belts.

\section{PATIENTS AND METHODS}

A retrospective cohort of severely injured [Injury Severity Score [ISS] $>12$ ] pediatric (age $<18$ years) rear occupants involved in a traffic MVC and treated at one of the two trauma centers in Southwestern Ontario (London Health Sciences Centre in London, Ontario, or Hotel Dieu Grace Hospital in Windsor, Ontario) from January 1, 2001, to December 31, 2010, were reviewed. An ISS of greater than 12 was selected as the entry cut point for this study because the inclusion criteria for the comprehensive data set for severe or major injury in the province of Ontario is ISS greater than 12 (note that $90 \%$ of patients had an ISS of $\geq 15$ ). Analysis included all passenger vehicle, light truck, or van pediatric rear occupants. Excluded patients were those who died at the scene, died after being treated only at a nontrauma hospital, and front occupants.

Demographic, injury, crash, and outcome data were obtained from trauma registries at both trauma centers, based on clinical notes, procedure notes, radiology reports, operating room notes, and coroner's reports. All injuries were coded using the Abbreviated Injury Scale (AIS) ${ }^{19}$ and ISS to reflect overall severity of injuries. Police crash reports and ambulance call reports were requested on each patient to obtain more detailed information on the crash including impact types and location, occupant seating position, restraint use, ejection from the vehicle, extrication procedures, and collision scene data. For protective device analyses, the minimally acceptable ageappropriate restraint use was defined as an infant/child/booster seat for a child 8 years or younger; for adolescents, a combination lap-shoulder belt.

Descriptive analyses were completed. Data were compared for the two pediatric age groups, based on their preferred age-appropriate restraint systems using $\chi^{2}$ for proportions of categorical data and nonparametric Mann-Whitney U-test for continuous variables. All continuous variables were checked for normality with the Shapiro-Wilk test. As data were all nonnormally distributed, medians and interquartile ranges were presented. A $p<0.05$ was considered statistically significant.

Multivariate logistic regression analysis was undertaken to determine the effect of various patient and crash risk factors on a severe injury in a body region, defined as a maximum Abbreviated Injury Scale score (MAIS) of 4 to 6, signifying severe, critical, and maximum injury, respectively. ${ }^{19}$ Separate models were developed for severe head injury and severe abdominal injury because these injuries were found to be statistically different between children and adolescent rear occupants. Possible confounders identified a priori were age (years), ISS, use of age-appropriate restraints, vehicle type, collision type (side-impact crash and single MVC), impact with a moving object, extrication required, and rear-occupant position (left, middle, or right). A backward elimination strategy was used to include all statistically and clinically significant variables. ${ }^{20}$ The model was sequentially fit and refit, removing the variable with the highest $p$ value, based on the Wald test, until the final model was determined, which included all statistically and clinically significant terms. The final model was used to determine the estimated odds (OR and $95 \% \mathrm{CI}$ ) of severe head or severe abdominal injury among pediatric rear occupants, adjusted for confounders. All analyses were performed using Predictive Analytics SoftWare (PASW) Statistics 18 (SPSS Inc., Chicago, IL).

\section{RESULTS}

The patient demographics and injury profiles for the two pediatric age groups are presented in Table 1 . There were 36 children $(34 \%)$ aged birth to 8 years (requiring child/ booster seating) and 70 adolescents (66\%) aged 9 years to 17 years (requiring lap-shoulder belt). Statistically significant injury differences across all body regions includes the abdomen, with a higher proportion of injury $(p=0.025$, Table 1$)$ and a greater severity of injury in the adolescent group ( $p=$ 0.020 , Table 1) and the head, with a greater proportion of children up to 8 years with severe injury $(p<0.001)$. Other outcome variables for pediatric survivors are presented in Table 2.

A comparison of crash details for the two pediatric age groups is presented in Table 3 . There were statistically more adolescents requiring extrication $(p=0.035)$. The type of impact also differed between the age groups with more sideimpact crashes in children and more single-motor vehicle crashes, which includes rollovers and impact with fixed objects for adolescents $(p=0.007)$.

Protective devices were used in $75 \%$ and $53 \%$ of injured children and adolescents, respectively. The distribution of protective devices differed for the child and adolescent groups, with $77 \%$ of restrained children in an infant/child/booster seat ( 1 infant seat, 5 children safety seats used incorrectly, 13 child safety seats used correctly, and 1 booster seat) and $92 \%$ of restrained adolescents in a lap-shoulder belt $(p<0.001)$. One youth in each group also had a side-airbag deploy. Appropriate age-dependent devices were documented in $56 \%$ and $47 \%$ of all children and adolescents, respectively $(p=0.412)$. To further elucidate the factors involved with increased odds of sustaining severe injuries, while controlling for potential 
TABLE 1. Patient and Injury Profiles, by Age Group, for Severely Injured Pediatric Rear-Occupant MVC Patients

\begin{tabular}{lccr}
\hline Variable & $\begin{array}{c}\text { Children 0-8 y } \\
(\mathbf{n}=\mathbf{3 6})\end{array}$ & $\begin{array}{c}\text { Adolescents 9-17 } \\
(\mathbf{n}=\mathbf{7 0})\end{array}$ & $\boldsymbol{p}$ \\
\hline Male & $52.8 \%$ & $51.4 \%$ & 0.895 \\
Arrive direct & $50.0 \%$ & $38.6 \%$ & 0.260 \\
Age, y & $4.5(7)$ & $15(3)$ & $<\mathbf{0 . 0 0 1}$ \\
Injury profile & & & \\
MAIS head/neck & $5(1)$ & $4(2)$ & 0.136 \\
MAIS face & $2(2)$ & $2(1)$ & 0.636 \\
MAIS thorax & $3(1)$ & $3(1)$ & 0.600 \\
MAIS abdomen & $2(1)$ & $3(2)$ & $\mathbf{0 . 0 2 0}$ \\
MAIS extremities & $3(1)$ & $3(1)$ & 0.397 \\
MAIS external & $1(0)$ & $1(0)$ & 0.498 \\
Severe injuries (MAIS 4-6) & & & \\
Head & $77.8 \%$ & $38.6 \%$ & $<\mathbf{0 . 0 0 1}$ \\
Neck & $0 \%$ & $1.4 \%$ & 1.000 \\
Thorax & $13.9 \%$ & $15.7 \%$ & 0.804 \\
Abdomen & $5.6 \%$ & $22.9 \%$ & $\mathbf{0 . 0 2 5}$ \\
Extremities & $0 \%$ & $5.7 \%$ & 0.144 \\
ISS & $26(21)$ & $26(16)$ & 0.716 \\
Mortality rate & $16.7 \%$ & $5.7 \%$ & 0.68 \\
\hline Categorical data are presented as & percentages; continuous data are presented as \\
median (interquartile range); boldface indicates statistical significance. & \\
\hline
\end{tabular}

confounders, multivariate logistic regression analysis was undertaken (Tables 4 and 5).

For severe head injuries (Table 4), as age and ageappropriate restraint use increased, there was a corresponding decrease in the odds of sustaining a severe head injury $(p<$ $0.001)$. Increasing the overall severity of injuries in the rear occupants increased the odds of sustaining a severe head trauma $(p<0.001)$. For example, the addition of one serious injury (MAIS score of 3 , which is a $3^{3}=9$ unit increase in ISS) would more than triple the occupant's odds of sustaining a severe head injury $\left(\mathrm{OR},[1.134]^{9}=3.10\right]$. Moreover, being seated in the middle rear increased the odds of severe head injury by 6.2 times $(95 \% \mathrm{CI}, 1.4-26.1 ; p=0.013)$.

An injury and protective device analysis of younger children was undertaken, stratified by age groups based on recommended type of restraint $(0-1$ year $[n=13], 2-4$ years

TABLE 2. Outcome Data for Survivors Only, by Age Group, for Severely Injured Pediatric Traffic Collision Patients

\begin{tabular}{lccc}
\hline Variable & $\begin{array}{c}\text { Surviving Children } \\
\mathbf{0 - 8} \mathbf{~ y ~ ( n = 3 0 )}\end{array}$ & $\begin{array}{c}\text { Surviving Adolescents } \\
\mathbf{9 - 1 7} \mathbf{~ y ~ ( n = 6 6 ) ~}\end{array}$ & $\boldsymbol{p}$ \\
\hline SCU LOS, d & $3(5)$ & $3(8)$ & 0.831 \\
Hospital LOS, d & $9(16)$ & $9(13)$ & 1.000 \\
Discharged to & & & 0.734 \\
Home & $80.0 \%$ & $72.7 \%$ & \\
Acute care & $6.7 \%$ & $12.1 \%$ & \\
Rehabilitation & $10.0 \%$ & $13.6 \%$ & \\
Other & $3.3 \%$ & $1.5 \%$ &
\end{tabular}

Categorical data are presented as percentages; continuous data are presented as median (interquartile range).

LOS, length of stay; SCU, special care unit.
TABLE 3. Crash Details for Severely Injured, Pediatric Rear Occupants in Traffic Collisions, 2001-2010

\begin{tabular}{|c|c|c|c|}
\hline Variable & $\begin{array}{c}\text { Children 0-8 y } \\
(n=36)\end{array}$ & $\begin{array}{l}\text { Adolescents } 9-17 y \\
(n=70)\end{array}$ & $p$ \\
\hline Position in rear & & & 0.833 \\
\hline Left rear & $22.2 \%$ & $15.7 \%$ & \\
\hline Middle/behind middle & $22.2 \%$ & $21.4 \%$ & \\
\hline Right rear & $25.0 \%$ & $25.7 \%$ & \\
\hline Rear not further specified & $30.6 \%$ & $37.1 \%$ & \\
\hline Ejection & $20.0 \%$ & $24.2 \%$ & 0.629 \\
\hline Extrication & $14.3 \%$ & $33.8 \%$ & 0.035 \\
\hline Primary Impact & & & 0.077 \\
\hline Frontal & $27.3 \%$ & $54.3 \%$ & \\
\hline Ride side & $31.8 \%$ & $17.1 \%$ & \\
\hline Left side & $18.2 \%$ & $22.9 \%$ & \\
\hline Rear & $22.7 \%$ & $5.7 \%$ & \\
\hline Collision detail & & & 0.070 \\
\hline Impact with moving object & $72.2 \%$ & $49.3 \%$ & \\
\hline Impact with fixed object & $13.9 \%$ & $30.4 \%$ & \\
\hline Vehicle rollover & $13.9 \%$ & $20.3 \%$ & \\
\hline Passenger vehicle & $63.9 \%$ & $70.0 \%$ & 0.523 \\
\hline Age-appropriate restraint use & $55.6 \%$ & $47.1 \%$ & 0.412 \\
\hline Impact type & & & 0.007 \\
\hline Approaching/Head on & 13.9 & 17.4 & \\
\hline Side impact crash & 47.2 & 23.2 & \\
\hline Rear & 13.9 & 2.9 & \\
\hline Sideswipe & 2.8 & 7.2 & \\
\hline Single MVC & 22.2 & 49.3 & \\
\hline
\end{tabular}

$[\mathrm{n}=5]$, and 5-8 years $[\mathrm{n}=18])$. The analysis demonstrated that infants younger than 1 year sustained the highest rate of severe head injury $(100 \%, 40 \%, 72 \%$, respectively; $p=0.021)$, despite all infants having some sort of restraint. Only $28 \%$ of children aged 5 years to 8 years were restrained appropriately in a child safety seat or booster.

For severe abdominal injuries (Table 5), the same association of increasing ISS and increasing odds of severe abdominal injury was demonstrated $(p=0.020)$, but a reverse relationship existed with age and the use of age-appropriate restraints. In the abdominal injury group, the rear occupant's odds of sustaining a severe injury was increased with age $(p=0.030)$, and as appropriate restraint use increased $(p=0.034)$, more adolescents using a lap-shoulder belt sustained a severe abdominal injury.

Injury profiles for the head and abdomen are presented in Figure 1. There were statistically more skull fractures $(p=0.044)$, subdural hematomas (SDHs) $(p=0.001)$, subarachnoid hemorrhage $(p=0.014)$, brain contusions $(p=0.003)$, and edema ( $p=0.004)$ in the age group 0 year to 8 years as compared with the adolescents. There were no statistically significant differences in the types of abdominal injuries between the two age groups $(p>0.05)$.

A subanalysis of injury patterns stratified by restraint use found no differences in the abdominal injury patterns for children ( $0-8$ years). For adolescents, there were statistically more jejunum-ileum injuries in the restrained occupants compared with unrestrained $(17 \%$ vs. $0 \% ; p=0.025)$. For head 
TABLE 4. Final Logistic Regression Model With Outcome Variable Severe Head Injury

\begin{tabular}{lccccc}
\hline Variable & $\boldsymbol{\beta}$ & SE & OR & $\mathbf{9 5 \%}$ CI & $\boldsymbol{p}$ \\
\hline Age, y & -0.179 & 0.050 & 0.836 & $0.758-0.923$ & $<\mathbf{0 . 0 0 1}$ \\
ISS & 0.126 & 0.030 & 1.134 & $1.069-1.204$ & $<\mathbf{0 . 0 0 1}$ \\
$\begin{array}{l}\text { Lack of age-appropriate } \\
\quad \text { restraint }\end{array}$ & 1.252 & 0.573 & 3.497 & $1.137-10.756$ & $\mathbf{0 . 0 2 9}$ \\
Left rear & & & & & \\
Middle & 0.583 & 0.736 & 1.791 & $0.423-7.574$ & 0.428 \\
Right rear & 1.828 & 0.732 & 6.221 & $1.482-26.113$ & $\mathbf{0 . 0 1 3}$ \\
Constant & -0.239 & 0.673 & 0.787 & $0.210-2.946$ & 0.722 \\
\hline
\end{tabular}

injury patterns, there were statistically more SDH (58\% vs. 10\%; $p=0.022)$ and subarachnoid hemorrhage ( $54 \%$ vs. $0 \% ; p=0.005)$ for restrained children compared with unrestrained children. In adolescents, there was more than double the number of unrestrained rear occupants with a severe head injury compared with restrained $(56 \%$ vs. $22 \% ; p=0.004)$. Specifically, there were more vault fractures $(32 \%$ vs. $8 \% ; p=0.017)$, skull fractures $(35 \%$ vs. $11 \% ; p=0.016)$ and SDH $(27 \%$ vs. $6 \%$; $p=0.016)$ in unrestrained compared with restrained group, respectively.

\section{DISCUSSION}

In this study, we describe the injury patterns, outcomes, and associated crash factors for pediatric rear occupants. Our data suggest that rear-seated younger children experience severe head injuries associated with the lack of appropriate restraint, the middle rear seating position, and side-impact crashes. In contrast, adolescents experience severe abdominal injuries associated with the use of appropriate restraints and extrication from single-vehicle crashes. Our data may aid laboratory crash tests for child and adolescent rear occupants.

MVCs are a major source of injury, death, and disability for children and adolescents. As a result, there has been a considerable amount of injury collision research undertaken to assess vehicle design and safety ranging from crash tests with anthropometric dummies to epidemiologic and biomechanical studies based on real-world crash data, such as the Crash Injury Research Engineering Network database. These in vivo models for injury tolerance based on Crash Injury Research Engineering Network crash data are particularly important for pediatric crash victims, whose size, proportions, and developmental variability are not accurately reflected in crash test dummies, and consequently, real-world MVC injury patterns are not necessarily reproduced by in vitro testing. 4

Previous research has identified factors including height, weight, seating height, and development that put children at higher risk for injury, particularly in side impacts. ${ }^{8,21}$ One study found that $35 \%$ of restrained children with injuries of AIS score 3 were involved in a side-impact collision, representing the most substantial crash injury risk for children. ${ }^{22}$ Another study found that children in side impacts had more than three times the odds of sustaining severe injuries with ISS of greater than 15, compared with children in frontal crashes, and 2.5 times greater risk of sustaining an injury in the head of AIS score of $2+.{ }^{23}$ Our data support this increased risk of injury from side-impact collisions for children 8 years or younger. Nearly half of the collisions resulting in severe injuries in this age group were the result of a side-impact crash, with $50 \%$ of identified primary impacts on the lateral side of the vehicle.

Previous injury pattern analyses found that the most children $(72 \%)$ in side-impact crashes were seated in the rear, and the majority of the significant injuries were to the head $(39 \%){ }^{21}$ All of the children in this latter study aged 5 years to 15 years who sustained a serious head injury were restrained, except one child, and were injured by head contact with the interior of the vehicle. We found a similar incidence of severe head injury in 9 -year-olds to 17 -year-olds (39\%), but this was doubled in the children 8 years or younger $(78 \%)$. The incidence of skull fractures in our younger group was also nearly double, suggesting a higher proportion of head injuries resulting from actual impact to the head. In contrast, there were no significant differences between the age groups in the frequency of diffuse axonal injury, a deceleration-type injury. The greater incidence of head injuries in our young children may be caused by the fact that only $55 \%$ of children in our study were restrained with an appropriate child restraint system. Lack of age-appropriate restraint resulted in a 3.5-fold increase in odds of severe head injury. Our findings agree with previous work on children that found a more than fourfold increase in risk of significant head injury associated with inappropriate restraint use ${ }^{24}$ as well as research that demonstrated suboptimally restrained children received a greater proportion of moderate-tosevere (AIS score, $2+$ ) injuries. ${ }^{25}$

The determination of the increased risk of head injuries and other injuries, as well as the dangers of both side and frontal impacts for children have led to the recommendation by American Academy of Pediatrics for placing children in the rear of the vehicle. ${ }^{26}$ The Canadian Paediatric Society Position Statement agrees with this recommendation but also specifies the middle rear position as the preferred, most protective seating position for a single-child occupant because the passenger will be the farthest possible distance from side impacts and side air bags. ${ }^{27}$ The center seat is also recommended owing to the perception that the center position provides a more snug fit of the child restraint system. ${ }^{28}$ There has been conflicting evidence as to whether the rear middle position is protective for children. One study on children 5 years or younger found that those seated in the center rear position experienced a $12 \%$ higher injury risk than those seated in the left position but a 3\% lower injury risk

TABLE 5. Final Logistic Regression Model With Outcome Variable Severe Abdominal Injury

\begin{tabular}{lccccc}
\hline Variable & $\boldsymbol{\beta}$ & SE & OR & $\mathbf{9 5 \%}$ CI & $\boldsymbol{p}$ \\
\hline Age, y & 0.133 & 0.061 & 1.142 & $1.013-1.287$ & $\mathbf{0 . 0 3 0}$ \\
ISS & 0.056 & 0.024 & 1.058 & $1.009-1.109$ & $\mathbf{0 . 0 2 0}$ \\
Use of age-appropriate & 1.344 & 0.635 & 3.834 & $1.104-13.309$ & $\mathbf{0 . 0 3 4}$ \\
$\quad$ restraint & & & & & \\
Left rear & -1.433 & 1.177 & 0.239 & $0.024-2.396$ & 0.224 \\
Middle & 0.158 & 0.767 & 1.171 & $0.261-5.265$ & 0.836 \\
Right rear & 0.267 & 0.712 & 1.306 & $0.323-5.273$ & 0.708 \\
Constant & -5.575 & 1.417 & & & \\
\hline
\end{tabular}




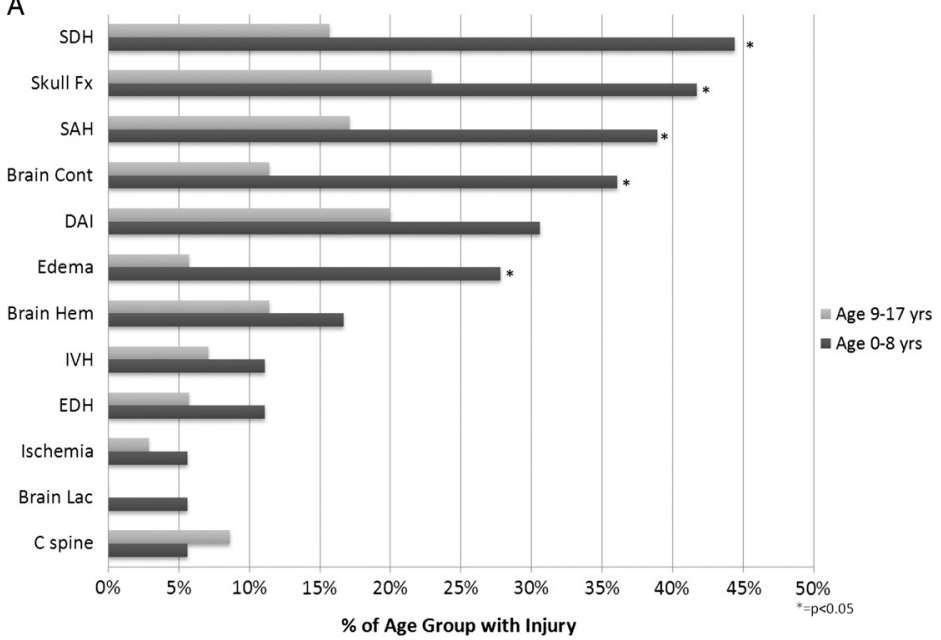

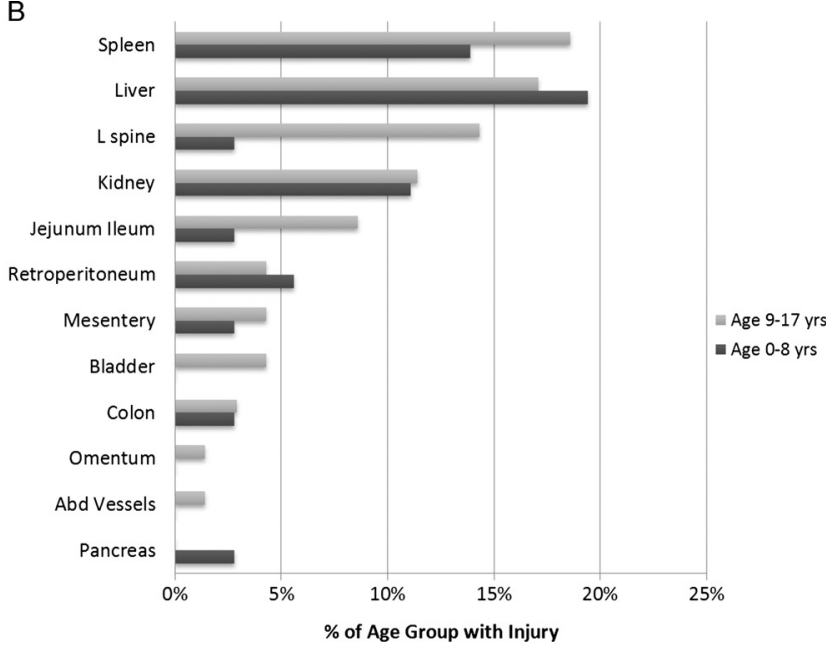

Figure 1. Injury profiles for both age groups. $A$, Head injury profile; $B$, abdominal injury profile. *Statistically significant differences between age groups $(p<0.05)$.

than those seated in the right rear position. ${ }^{29}$ More recently, researchers found children aged 0 year to 3 years seated in the center rear position had a $43 \%$ lower risk of injury compared with the two other rear outboard positions, and this decreased risk was more apparent in side-impact crashes. ${ }^{30}$ While these data were limited to children who sustained an injury with AIS score of 2 or greater (signifying a "moderate" injury), ${ }^{19}$ this level of injury severity was estimated by parents via a telephone survey. In our study, all of the children had severe injuries with an overall ISS of 12 or greater, as scored by trained trauma data analysts. Our patients were more likely to be severely injured. (To have an ISS $\geq 12$, an individual needed as least one AIS score $=2$ [moderate] injury and an AIS score $=3$ [serious] injury, or an injury with AIS score $=4 .{ }^{19}$ )

Our analysis demonstrated that all restrained infants sustained a severe head injury, and children in the rear middle seating position had a 6.6 times increased odds of sustaining a severe head injury for rear occupants. This substantiated crashworthiness testing performed by Transport Canada who found that the children positioned in the center rear had a higher occurrence of head injuries owing to both head contact with the center console and the lack of an universal anchorage system in the middle seating position. ${ }^{17}$ Lack of universal anchorage system in the center rear of some automobile models leaves the seatbelt as the only option for installation of the safety seat, which can result in greater forward excursions of the infant seat and a greater potential for contact with the console. ${ }^{17}$ This injury mechanism corresponds with our reported injury patterns of $100 \%$ of infants sustaining a severe head injury. The $72 \%$ severe head injuries sustained by the older children (5-8 years) may be a direct result of lack of restraint use in this age group (72\% unrestrained).

While head injuries are more prevalent for the youngest occupants, school-aged children and teens more often experience "seatbelt syndrome," which includes a spectrum of intraabdominal visceral injuries and fractures of the thoracolumbar spine (Chance fractures) owing to "jack knifing." ${ }^{13}$ More recently, "submarining" has been proposed as an injury mechanism in children and adolescents where the lap belt rides up the abdomen because of their less developed bony thorax, pelvis, and anterior superior iliac spines. ${ }^{13,24,31}$ Our findings may support both mechanisms given the increased proportion of lumbar spine and splenic injuries. In particular, adolescents aged 9 years to 17 years had statistically more severe abdominal injuries with a higher median MAIS of 3, signifying a serious injury. ${ }^{19}$ Logistic regression modeling showed that adolescents properly restrained by a lap-shoulder belt had a 3.8 increased odds of sustaining a severe abdominal injury, indicating a need to design and test restraint systems in the rear seat that can minimize the abdominal injury potential for the adolescent population because proper use of seatbelts will always be recommended for adolescent rear occupants.

Our study has several limitations. First, our data do not represent all crashes, but crashes in which severe injuries were sustained and pediatric rear occupants were treated at one of our two trauma centers. The lack of an integrated crash investigation trauma center database in Canada limits injury data available for study to the trauma registries, which resulted in a smaller sample size of patients for analysis. Second, the most severely injured children who die at the scene have been excluded because coroner data for nonhospitalized children were not accessible. Third, police crash reports were only available for $54 \%$ of patients, limiting our ability to analyze primary vehicle impact location data in all MVCs. While crash reports are routinely requested by the Trauma Program, they are not received for all patients. Scene data were also abstracted from ambulance call reports and personnel at the scene, as available. Finally, as crash investigations were not completed in all cases, the change in velocity and amount of intrusion in the vehicle were not available for analysis, both of which are important factors in the biomechanics of injury tolerance during a crash. ${ }^{8}$

\section{CONCLUSION}

The recommendations for rear seat positioning of children are well supported; ${ }^{6-9}$ however, further study on injury patterns and mechanisms may help to decrease the injury risk for 
pediatric rear occupants. Our results demonstrated that rearoccupant children were more likely to have a severe head injury when there was a lack of use of age-appropriate child restraint systems and when they were positioned in the middle rear. Adolescents were found to have more severe abdominal injuries associated with increased use of a lap-shoulder belt, likely owing to jack knifing or submarining given the relative frequency of lumbar spine and upper-abdominal injuries, respectively. The correlation of real-world MVC data can aid the design of crashworthiness investigations and education of the public on both occupant positioning and proper restraints. Renewed advocacy and recommendations for safety standards on child protective restraints and preferred seating positions are needed.

\section{AUTHORSHIP}

All authors, T.C.S., K.M., M.S., J.-L.C., J.G., and D.D.F., have made substantial contributions to the conception, content, interpretation, and critical revision of the article. T.C.S. also undertook the data analysis. All authors also approve the article, as it has been submitted.

\section{ACKNOWLEDGMENT}

We thank Cynthia Dettloff, Joyce Williamson, and Denise Polgar of the Trauma Program, LHSC, London, Ontario, and Suzanne McKenzie from the Trauma Program, HDGH in Windsor, Ontario, for providing data and support for the preparation of this article.

\section{DISCLOSURE}

The authors declare no conflicts of interest.

\section{REFERENCES}

1. Canadian Institute for Health Information. National Trauma Registry: 2007 Injury Hospitalizations Highlights Report (In Focus: Pediatric Injury Hospitalizations in Canada). 2005-2006. Ottawa, Ontarion, Canada: CIHI; 2008.

2. Canadian Institute for Health Information. Ontario Trauma Registry 2011 Report: Major Injury in Ontario. 2009-2010 Data. Ottawa, Ontarion, Canada: CIHI; 2011.

3. Charyk Stewart T, Polgar D, Parry N, et al. Moving From Evidence to Action Prioritisation of Pediatric Injury Issues for Focused Injury Prevention Programming. Auckland, New Zealand: Trauma Association of Canada: Combined Annual Scientific Meeting of the TAC and the Australasion Trauma Society; 2008.

4. Sherwood CP, Shaw CG, Van Rooij L, et al. Prediction of cervical spine injury risk for the 6-year-old child in frontal crashes. Traffic Inj Prev. 2003;4:206-213.

5. Buntain WL. Management of Pediatric Trauma. Philadelphia, PA: W.B. Saunders Company; 1995:13-16.

6. Arbogast KB, Kallan MJ, Durbin DR. Front versus rear seat injury risk for child passengers: evaluation of newer model year vehicles. Traffic Inj Prev. 2009;10:297-301.

7. Smith KM, Cummings P. Passenger seating position and the risk of passenger death in traffic crashes: a matched cohort study. Inj Prev. 2006; 12:83-86.

8. Ehrlich PF, Brown JK, Sochor MR, et al. Factors influencing pediatric Injury Severity Score and Glasgow Coma Scale in pediatric automobile crashes: results from the Crash Injury Research Engineering Network. $J$ Pediatr Surg. 2006;41:1854-1858.

9. Lennon A, Siskind V, Haworth N. Rear seat safer: seating position, restraint use and injuries in children in traffic crashes in Victoria, Australia. Accid Anal Prev. 2008;40:829-834.

10. Tylko S, Dalmatos D. Protection of Rear Seat Occupants in Frontal Crashes. Washington, DC: The 19th International Technical Conference on the Enhanced Safety of Vehicles (ESV); 2005.

11. Bidez MW, Burke DS, King D, et al. A Critical Safety Need for Children Ages 9 to 12 in the Rear Seat. Munich, Germany: Protection of Children in Cars 5th International Conference; 2007.

12. Achildi O, Betz RR, Grewal H. Lapbelt injuries and the seatbelt syndrome in pediatric spinal cord injury. J Spinal Cord Med. 2007;30:21-24.

13. Santschi M, Echave V, Laflamme S, et al. Seat-belt injuries in children involved in motor vehicle crashes. Can J Surg. 2005;48:373-376.

14. Bidez MW, Syson S. Kinematics, Injury Mechanism and Design Considerations for Older Children in Adult Torso Belts. Detroit, MI: Society of Automotive Engineers (SAE) 2001 World Congress; 2001.

15. Durbin DR. Effects of seating position and appropriate restraint use on the risk of injury to children in motor vehicle crashes. Pediatrics. 2005; 115:e305-e309.

16. Berg MD, Cook L, Corneli HM, Vernon DD, Dean JM. Effect of seating position and restraint use on injuries to children in motor vehicle crashes. Pediatrics. 2000;105:831-835.

17. Tylko S, Dalmotas D. Interactions of Rear Facing Child Restraints With the Vehicle Interior During Frontal Crash Tests. Washington, DC: The 22nd International Technical Conference on the Enhanced Safety of Vehicles (ESV); 2011.

18. Maltese MR, Locey CM, Jermakian JS, et al. Injury causation scenarios in belt-restrained nearside child occupants. Stapp Car Crash J. 2007;51: 299-311.

19. Association for the Advancement of Automotive Medicine. The Abbreviated Injury Scale: 1990 Revision. Des Plaines, IL: AAAM: 1990.

20. Hosmer DW, Lemeshow S. Applied Logistic Regression. New York, NY: Wiley; 1989:82-134.

21. Arbogast KB, Moll EK, Morris SD, et al. Factors influencing pediatric injury in side impact collisions. J Trauma. 2001;51:469-477.

22. Langwieder K, Hell W, Willson H. Performance of Child Restraint Systems in Real-Life Lateral Collisions. Albquerque, NM: Proceedings of the 40th Stapp Car Crash Conference: Society of Automotive Engineers (SAE); 1996.

23. Orzechowski KM, Edgerton EA, Bulas DI, et al. Patterns of injury to restrained children in side impact motor vehicle crashes: the side impact syndrome. J Trauma. 2003;54:1094-1101.

24. Winston FK, Durbin DR, Kallan MJ, et al. The danger of premature graduation to seat belts for young children. Pediatrics. 2000;105:1179-1183.

25. Brown J, McCaskill ME, Henderson M, et al. Serious injury is associated with suboptimal restraint use in child motor vehicle occupants. $J$ Paediatr Child Health. 2006;42:345-349.

26. Durbin DR. Child passenger safety. Pediatrics. 2011;127:e1050-e1066.

27. Canadian Pediatric Society. Transportation of infants and children in motor vehicles. Available at: http://www.cps.ca/english/statements/IP/ IP08-01.pdf. Accessed January 26, 2012.

28. American Academy of Pediatrics. Recommendations on car seats. 2011. Available at: http://www.healthychildren.org/English/news/Pages/AAPUpdates-Recommendations-on-Car-Seats.aspx. Accessed January 25, 2012.

29. Lund U. The effect of seating location on the injury of properly restrained children in child safety seats. Accid Anal Prev. 2005;37:435-439.

30. Kallan MJ, Durbin DR, Arbogast KB. Seating patterns and corresponding risk of injury among 0 - to 3 -year-old children in child safety seats. Pediatrics. 2008;121:e1342-e1347.

31. Anderson P, Rivara F, Maier R, et al. The epidemiology of seat belt associated injuries. J Trauma. 1991;31:60-67. 